\title{
A IDEIA DE CULTURA E SUA ATUALIDADE PARA O ENSINO-APRENDIZAGEM DE LE/L2
}

\section{Edleise MENDES*}

- RESUMO: Nas últimas décadas, muitos estudos e pesquisas desenvolvidos no campo do ensino/aprendizagem de línguas, sobretudo de línguas estrangeiras e segundas, têm-se dedicado a discutir a importância da cultura e das relaçôes interculturais como dimensôes integrantes do processo de aprendizagem. Essa preocupação tem como princípio o fato de que ensinar e aprender uma língua é um processo muito mais amplo e complexo do que a simples transmissão e apreensão de estruturas formais e de regras de utilizaçáo dessas estruturas. Neste artigo, proponho-me a revisitar a ideia de cultura para, em seguida, estabelecer a sua relação com a língua, ressaltando a atualidade desse tipo de reflexão para a área de ensino-aprendizagem de LE/L2, especialmente com foco na língua portuguesa. Entre outros aspectos, desejo mostrar que as tendências contemporâneas para o ensino e a formação de professores de línguas reconhecem que as abordagens de ensinar e aprender, sejam quais forem as suas orientaçôes teóricas, não devem isolar a língua da vida em que vivemos e da cultura ou culturas que a abrigam, como meio de assegurar uma educação linguística de qualidade e condizente com as exigências do mundo contemporâneo.

- PALAVRAS-CHAVE: Conceito de cultura. Língua e cultura. Ensino e aprendizagem de LE. Português língua estrangeira.

\section{Introdução}

Talvez não seja mais relevante, para muitos, ocuparem-se com reflexões sobre a ideia de cultura, sobretudo em tempos de globalização e liquidez de tudo, para usar uma metáfora de Zymunt Bauman. No entanto, mostrarei que essa ainda é uma discussão importante, sobretudo para aqueles que atuam no amplo campo da Linguística Aplicada e, mais especificamente, do ensino e aprendizagem de LE/L2, embora continue sendo essa uma tarefa complexa. Por um lado, devido ao próprio emaranhado de definiçóes e conceitos que cercam o termo ao longo de sua evolução no desenvolvimento das ciências sociais. Por outro, pela difícil tarefa de se definir e escolher que temas e áreas de interesse culturais devem ser abordados, sem correr o

\footnotetext{
* UFBA - Universidade Federal da Bahia. Instituto de Letras - Departamento de Letras Vernáculas. Salvador - BA - Brasil. 40170290 - edleise.mendes@gmail.com
} 
risco de tropeçar nos estereótipos, tão frequentes no cotidiano da sociedade, assim como nos planejamentos de cursos e elaboraçáo de materiais didáticos voltados para o ensino de línguas estrangeiras.

Nas últimas décadas, mesmo que tenhamos assistido a uma retomada do termo cultura, que frequenta os mais diferentes campos semânticos, essa proliferação e massificação da noção de cultura tem por vezes contribuído para uma certa banalização do termo e, não raro, para uma confusão conceitual, que nos obriga a revisar nossas próprias ideias e convicçóes sobre o que é a cultura e o que ela representa.

O que busco, desse modo, é chegar a uma ideia de cultura que, mais do que um conceito abrangente e totalizador, forneça-nos ferramentas para compreender o 'estar no mundo' do homem e todos os aspectos que envolvem essa vivência, dentro de seu grupo específico ou fora dele. Isso é fundamental para compreendermos como se dá a ancoragem entre a língua e a cultura e de que modo essa relaçáo e simbiose afetam o processo de ensinar e aprender línguas, em nosso caso específico, português como língua estrangeira / língua segunda. Como parte dessa empreitada, preciso voltar um pouco no tempo e refletir, mesmo que de maneira breve, sobre alguns pontos de parada nessa longa estrada na qual se desenvolveu, e ainda se desenvolve, um conjunto de ideias e pressupostos sobre uma das mais importantes dimensóes da vida humana - a dimensão cultural.

\section{A gênese de um conceito}

Em seu livro A noção de cultura nas ciências sociais, Cuche (1999) desenvolve uma genealogia do conceito de cultura, partindo da consideração do próprio significado da palavra. A evoluçáo semântica decisiva do vocábulo deu-se na França, a partir do século XVII, sendo depois transferida por empréstimo a outras línguas, como o inglês e o alemão. No entanto a palavra já figurava no vocabulário francês desde o século XIII, significando "[...] o cuidado dispensado ao campo ou ao gado ou parcela de terra cultivada”. No começo do século XVI, no entanto, o vocábulo já não significa o estado da coisa cultivada, mas surge com a acepção de "ação de cultivar a terra". (CUCHE, 1999, p.19).

A concepção de cultura num sentido figurado, significando a cultura do espírito, do desenvolvimento de uma faculdade, somente surgirá a partir da segunda metade do século XVI. Esse conceito, no entanto, não será bem aceito no meio intelectual e acadêmico até o século XVIII. A partir deste momento, o termo começa a exercer uma certa imposição, passando a ser utilizado, inicialmente, seguido de complementos, como: "cultura das artes", "cultura das letras", "cultura das ciências". Depois, num movimento crescente, 'cultura' se libera dos seus complementos e passa a ser empregada sozinha, para designar a formação, a educação do espírito. Em seguida, inversamente ao que foi observado anteriormente, a cultura deixa de ser vista como ação de instruir e volta a representar estado, mas "[...] estado do espírito cultivado 
pela instrução, estado do indivíduo 'que tem cultura'." Este será o uso consagrado no fim do século XVIII, o qual estigmatiza "um espírito natural e sem cultura", estabelecendo a oposição entre 'natureza' e 'cultura'. Com a influência dos pensadores do Iluminismo, para os quais a oposição 'natureza' e 'cultura' era fundamental, a palavra assume uma acepçáo mais ampla, passa a representar um caráter distintivo da espécie humana: “[...] é a soma dos saberes acumulados e transmitidos pela humanidade, considerada como totalidade, ao longo da sua história" (CUCHE, 1999, p.20-21).

No decorrer do século XIX, a preocupação com a reflexão sobre o homem, a sociedade e a questão maior da diversidade humana contribuiu para a criaçáo da sociologia e da etnologia como ciências autônomas. $\mathrm{O}$ ponto principal de reflexáo, sobretudo para a etnologia, centrava-se na compreensão da diversidade humana, partindo do postulado, herdado do Iluminismo, da especificidade humana, da unidade do homem. Como um caminho para se pensar a diversidade na unidade, sem lançar mão de uma resposta biológica, como a simples diferença de 'raças', os etnólogos vão eleger o conceito de 'cultura' como instrumento privilegiado para a sua reflexão. No entanto, embora nesse momento o vocábulo estivesse em evidência, ele era utilizado num sentido estritamente normativo. Os fundadores da etnologia e, de uma maneira geral, os pensadores da época vão atribuir ao termo um conteúdo puramente descritivo. $\mathrm{O}$ interesse era descrever o que é a cultura, tal como aparece nas sociedades humanas, e não o que ela deve ser. Por ser uma ciência ainda em constituição, cuja influência no meio intelectual da época náo era decisiva, a etnologia permitiu-se ficar à parte da discussáo sobre a oposição entre 'cultura' e 'civilização', a qual ainda dominava o cenário intelectual. Essa relativa autonomia epistemológica contribuiu para a introduçấo do conceito de cultura, com aceitaçóes desiguais, nos diferentes países onde a etnologia dava início ao seu desenvolvimento. No entanto, não havia um entendimento entre as diferentes 'escolas' sobre o uso do conceito, sobretudo com relação à dúvida sobre a necessidade de empregá-lo com uma acepção universalista ou particularista: a Cultura ou as culturas (CUCHE, 1999, p.35).

O que fundamentou, de forma mais direta, a busca por um conceito de cultura foi o dilema, que já possuía raízes na Antiguidade com os filósofos gregos e se estendeu até os nossos dias, da conciliação da unidade biológica e a grande diversidade cultural humana. Buscando resolver esse impasse é que as diferentes ciências buscaram elucidar/ construir um conceito de cultura que fosse válido cientificamente. Nessa tarefa, um dos ambientes mais férteis de discussão se deu no interior da antropologia. A fala de Geertz (1978, p.33) é bem clara quanto a essa missão:

A grande variação natural de formas culturais é, sem dúvida, não apenas o grande (e desperdiçado) recurso da antropologia, mas o terreno do seu mais profundo dilema teórico: de que maneira tal variaçáo pode enquadrar-se com a unidade biológica da espécie humana? 
As primeiras tentativas mais sistemáticas de se construir um conceito de cultura que conseguisse resolver o 'velho' dilema referido anteriormente, e que ao mesmo tempo tivesse força como instrumento científico, tiveram como fonte de inspiração as teorias do determinismo biológico e do determinismo geográfico, muito populares no final do século XIX e início do século XX. Essas teorias defendiam a ideia de que a diversidade cultural humana é condicionada por duas principais variáveis: o caráter biológico e o espaço geográfico. A primeira delas atribuía às diferenças genéticas dos povos a diversidade cultural observada. Desse modo, eram comuns, na época, as afirmaçóes de que determinadas 'raças' possuíam capacidades específicas inatas, enquanto outras eram privadas dessas capacidades. A segunda teoria, por sua vez, considerava que as especificidades culturais dos povos eram condicionadas por diferenças do ambiente físico, da geografia circundante. No entanto, nem o determinismo biológico nem o determinismo geográfico foram capazes de resolver o impasse de se compreender a unidade e a diversidade da espécie humana, uma vez que as diferenças entre os homens não podiam ser explicadas "[...] pelo seu aparato biológico ou pelo seu meio ambiente"

A primeira concepção de cultura como conceito científico, o qual é reconhecido, ainda hoje, como o primeiro conceito antropológico de cultura, foi formulado por Edward Burnett Tylor (1832-1917). Sintetizando o termo germânico Kultur e a palavra francesa civilisation, Tylor utilizou o vocábulo em inglês Culture, e assim o definiu: “[...] tomado em seu amplo sentido etnográfico é este o todo complexo que inclui conhecimentos, crenças, arte, moral, leis, costumes ou qualquer outra capacidade ou hábitos adquiridos pelo homem como membro de uma sociedade." (LARAIA, 1999, p.25). O grande mérito de Tylor, considerado o fundador da antropologia britânica, foi a sua preocupação metodológica, a busca por elaborar um conceito de cultura que pudesse auxiliar a abordagem efetiva dos fatos culturais de um modo geral e sistemático. Segundo Cuche (1999), ele foi o primeiro a se dedicar ao estudo da cultura sob diferentes aspectos: materiais, simbólicos, corporais, entre outros, e em todos os tipos de grupos humanos.

No entanto, o conceito desenvolvido por Tylor sofreu, e ainda sofre, um grande número de críticas, não só formuladas por seus contemporâneos, como Franz Boas, mas também por grande parte dos estudiosos sobre cultura que o sucederam. A crítica principal tinha como ponto central uma certa reação às ideias defendidas pelas teorias evolucionistas da cultura, as quais estabeleciam, através da comparação entre as diferentes culturas, o lugar pertencente a cada uma delas na escala evolutiva, ficando, de um lado, as culturas primitivas e, de outro, as culturas mais avançadas.

\footnotetext{
A partir do começo do século XX, muitos antropólogos, entre eles, Franz Boas, Wissler, Alfred Kroeber, Margareth Mead, Felix Keesing, Marshal Sahlins, refutaram essas teorias, demonstrando, através de exemplos colhidos na observação de diferentes grupos humanos, que é possível e comum existirem diferenças culturais muito grandes entre povos que habitam o mesmo ambiente físico, e que não existe correlação significativa entre as características genéticas dos diferentes grupos e o seu comportamento cultural (LARAIA, 1999).
} 
Era possível, então, como acreditavam os evolucionistas, cujo maior representante era Tylor, descobrir as leis universais de funcionamento das sociedades e culturas, além das leis e estágios gerais de evolução pelos quais as culturas primitivas passariam até chegar ao topo da escala, tornando-se uma cultura 'civilizada'. Embora esse "todo mais complexo" de Tylor, para citar a expressão usada por Geertz (1978, p.14), tenha contribuído para a imensa confusão conceitual que se estabeleceu em seguida, não se pode negar que ele deu o pontapé inicial para que, com diferentes interesses e olhares, muitos buscassem o desenvolvimento de um conceito de cultura "mais limitado", "mais especializado" e "teoricamente mais poderoso", como também observa Geertz. Ainda que seus sucessores encontrassem um grande número de motivos para criticá-lo, não podiam ignorar a sua importância como ponto de partida para o desenvolvimento de suas ideias.

\section{Diferentes visões, o mesmo problema}

Entre Edward Tylor e os nossos dias, a ideia de cultura evoluiu significativamente, seguindo diferentes tendências e correntes epistemológicas, as quais buscavam compreender o que é a cultura e como ela age nas diferentes dimensóes da existência humana. Muitos conceitos surgiram, alguns muito criticados, outros consagrados e tomados como referência para as reformulações subsequentes ${ }^{2}$. A partir daí, as discussóes e debates surgidos, principalmente, no âmbito da antropologia, produziram um dos conceitos mais poderosos, traduzido por diferentes variantes do que se denomina "o conceito antropológico de cultura", em oposição a definiçóes produzidas no interior de outras áreas do conhecimento, como a psicanálise, a sociologia, a semiótica etc.

De acordo com a tradiçấo antropológica, a cultura é definida como a totalidade de características de um grupo social. Assim, a cultura de um grupo ou classe representa um estilo de vida especial e distinto deste grupo ou classe, o que inclui os significados, os valores e as ideias, e como eles são refletidos nas instituiçóes, nas relaçóes sociais, nos sistemas de crenças, nos costumes e tradiçóes, no uso dos objetos e na vida material.

\footnotetext{
2 Náo citarei, nesta breve reflexáo, todos os diferentes momentos de discussão sobre o conceito de cultura, tarefa que foge ao escopo deste artigo. A partir do século XVIII, principalmente, muitas contribuiçóes, de diferentes correntes do pensamento e de diferentes estudiosos, colaboraram para a construção do complexo arcabouço de ideias e princípios que cercam o termo hoje. Para aqueles que desejam aprofundar-se mais sobre o assunto, destacarei alguns nomes que, a meu ver, contribuíram de forma decisiva para a evolução e compreensão do fenômeno da cultura: Burnett Taylor, Alfred Kroeber, Franz Boas, Emile Durkheim, LucienLévy-Bruhl, Bronislaw Malinowski, Margareth Mead, Ruth Benedict, Claude Lévy-Strauss, Leslie White, Roger Bastide, Max Weber, Pierre Bourdieu, Roger Keesing, Clifford Geertz, entre outros. Assim como personalidades diferentes marcaram a evolução das ideias sobre o conceito, algumas áreas do conhecimento dedicaram-se com mais afinco a esta discussáo, a exemplo da Etnologia, Antropologia e Sociologia, assim como diferentes escolas do pensamento: História Cultural, Evolucionismo, Difusionismo, Funcionalismo, Escola Cultura e Personalidade, Antropologia Cultural, Interacionismo, Aculturação (CUCHE, 1999; LARAIA, 1999).
} 
Esta concepção, considerada por muitos pensadores universalizante e totalizadora, que define o que é próprio de um determinado grupo em oposição a outros, foi, por vezes, duramente criticada, e ainda é nos dias de hoje de acordo com diferentes correntes do pensamento na contemporaneidade. No entanto, utilizei anteriormente a qualificação de "conceito poderoso" porque, embora seja motivo constante de críticas, é a concepção amplamente disseminada no pensamento científico e acadêmico, assim como no pensamento da coletividade de uma maneira geral.

No campo do ensino e aprendizagem de línguas, por exemplo, não raro nos deparamos com concepçóes que têm como base essa visão totalizadora, fechada e monolítica de cultura. A cultura, na maior parte dos livros didáticos de português língua estrangeira (PLE) ou segunda língua (PL2), por exemplo, aparece como ilustração, como conteúdo a ser ensinado, sobretudo dando-se destaque para aquilo que, no imaginário comum, representaria a riqueza cultural de um povo, como a culinária, as festas populares, as tradiçôes, o comportamento etc. A língua, desse modo, é vista apenas como um sistema que está a serviço da transmissão cultural, passada de geração a geração, de modo uniforme e estático.

De acordo com Neiva (1997), por exemplo, a concepção antropológica tradicional de cultura se baseia num conceito amplo e vago, abrangente e defensor da humanidade legítima dos povos. A cultura, entâo, evidenciaria as características que definem grupos sociais contrastantes, permitindo a atitude de reconhecimento do outro:

[...] seria uma abstração idealizada, um traço essencialmente distintivo que separaria os seres humanos em suas identidades sociais e que discriminaria a humanidade do mundo natural. A cultura é, então, vista como uma regra imanente de integração social, cujo propósito primordial é distinguir o que é nosso em oposição ao que é alheio. (NEIVA, 1997, p.133).

O autor critica, contundentemente, a ideia de cultura como "[...] uma barreira invisível que confere a cada ator social uma identidade coletiva e preciosa, a ser mantida e defendida a todo custo." (NEIVA, 1997, p.133). Ele caracteriza este fato como um 'equívoco irreparável' pois a ideia de estabilidade cultural, de imunidade às mudanças, não funciona como instrumento teórico numa era globalizante, fustigada pela ansiedade e pela mudança. Através de substantivos e expressóes como 'ilusão', 'miragem', 'sonho da totalidade' 'diálogo de surdos' o autor caracteriza a ideia de cultura disseminada pela tradição antropológica e tece a sua crítica, argumentando que a construção dessa visão surgiu como alternativa metodológica para a descrição de grupos sociais contrastantes e para responder às questóes raciais, biológicas e ambientais do comportamento humano. $\mathrm{O}$ dogma disciplinar que rege a noção de cultura repousa na distinção entre natureza e cultura, e na adoção de princípios e convenções que alteram o que é inato aos seres humanos. Neiva (1997, p.137) defende que para se chegar a uma noção efetiva de cultura, seria preciso mais do que uma simples descrição 
de costumes, crenças e instituiçóes que caracterizam os diferentes grupos humanos: "O objetivo da investigaçáo cultural seria entender o raciocínio que preside e que inspira atos à primeira vista sem sentido. Achar uma resposta que dê conta do raciocínio social no grupo estudado é um modo de conferir sentido ao que acontece."

Mas não foi este um dos objetivos que fizeram as diferentes correntes e tendências antropológicas buscarem edificar uma ideia de cultura? A evolução histórica do pensamento antropológico, desde a ideia inicial influenciada pelo iluminismo na busca do ideal da humanidade, do que o homem deve ser, em detrimento do que ele é, mostranos que nem mesmo os antropólogos estavam satisfeitos com o caráter totalizador, abrangente e idealizador da noção de cultura, como o próprio Eduardo Neiva admite. As sucessivas tentativas, a partir de Burnett Tylor, de se elaborar um conceito de cultura foram marcadas pela necessidade de eleição de um instrumento que, mais do que possibilitasse a observação e descrição de traços culturais de grupos humanos específicos, fosse "[...] mais limitado, mais especializado e, imagino, teoricamente mais poderoso para substituir o famoso 'o todo mais complexo' [...]", referindo-nos uma vez mais a Geertz (1978, p.14). Além disso, a observação feita por Neiva (1997) de que, apesar das críticas, o termo 'cultura' como conceito amplo e vago, continua a ser usado de forma maciça no meio acadêmico, nos meios de comunicação etc., só reforça o fato de que, embora tenha sofrido críticas ao longo de seu desenvolvimento, é a ideia de cultura desenvolvida no seio da antropologia que ensejou e enseja todo o pensamento a respeito da diversidade humana, principalmente na cena contemporânea. As críticas e queixas frequentes com relação à eficácia da noção de cultura, como aponta o próprio autor, devem-se menos às contribuiçôes do pensamento antropológico, do que à própria dimensão do significado da palavra cultura, posto que não é fácil resumir num conceito o que seja a complexidade humana.

Dentro da própria antropologia podemos identificar diferentes movimentos e esforços, muitas vezes contrastantes, no sentido de se erigir um conceito satisfatório de cultura. Este fato nos mostra que, embora o sentido universalizante e totalizador da ideia de cultura seja tomado como central no desenvolvimento do pensamento antropológico, alguns esforços buscaram contribuir para um deslocamento do foco original e uma consequente tentativa de renovação do conceito. Esse fato foi muito importante para que outras áreas que não a antropologia pudesse reelaborar o conceito à luz de suas teorias e visóes de mundo, tal como acorreu, nos últimos 10 anos, na área da Linguística Aplicada.

Uma das vertentes de discussão, por exemplo, que contribuiu para uma certa renovação da ideia de cultura surgiu a partir dos estudos sobre "aculturação"3. Principalmente no decorrer da década de 60, sobretudo com as contribuições do

Termo que significa "[...] o conjunto de fenômenos que resultam de um contato contínuo e direto entre grupos de indivíduos de culturas diferentes e que provocam mudanças nos modelos culturais iniciais de um ou dos dois grupos." (CUCHE, 1999, p.115). Os estudos sobre aculturação, até o seu ponto alto de desenvolvimento, na década de 60, com Roger Bastide, tiveram a contribuição de importantes expoentes 
sociólogo e antropólogo Roger Bastide, os fenômenos culturais passaram a ser estudados considerando-se as diferentes configuraçóes das relaçóes sociais, que podem fornecer quadros de integração, de competição, de conflito etc. Ou seja, nas situaçóes de aculturação, não se pode falar em culturas "puras", ou unicamente "doadoras" ou "receptoras", pois nenhuma cultura existe em 'estado puro', sem ter sofrido influências ou interferências ao longo de sua evolução. Os processos de aculturação, dessa forma, são um fenômeno universal, o qual apresenta graus e formas diversificados. Considerar, portanto, as relações interculturais e as situações de conflito em que elas se dão contribuiu para renovar a concepção de cultura como algo dinâmico; toda cultura, dessa forma, "[...] é um processo permanente de construção, desconstrução e reconstrução" (CUCHE, 1999, p. 137).

A cultura, a partir dos estudos sobre os processos de aculturação, passou a ser compreendida como um conjunto dinâmico e complexo, cujos elementos integradores provêm de fontes diversas no espaço e no tempo. Segundo Cuche (1999, p.140) “[...] não existem, consequentemente, de um lado as culturas 'puras' e de outro, as culturas 'mestiças'. Todas, devido ao fato universal dos contatos culturais, são, em diferentes graus, culturas 'mistas', feitas de continuidades e descontinuidades."

Um outro modo de olhar para a cultura, que não posso deixar de mencionar por ser um dos estudos mais significativos dentre a vasta literatura sobre o assunto, é o trabalho desenvolvido por Clifford Geertz (1978), em A interpretação das culturas. Neste estudo, Geertz assume buscar um conceito de cultura mais limitado, mais especializado, que possa atender com mais especificidade às exigências científicas, isto é, seja "teoricamente mais poderoso", em oposição ao que ele denomina o "todo mais complexo" que caracteriza as definiçóes antropológicas tradicionais de cultura, como eu já havia feito referência em duas ocasióes anteriores. Em suas próprias palavras:

O conceito de cultura que eu defendo [...] é essencialmente semiótico. Acreditando, como Max Weber, que o homem é um animal amarrado a teias de significados que ele mesmo teceu, assumo a cultura como sendo essas teias; portanto, não como uma ciência experimental em busca de leis, mas como uma ciência interpretativa, à procura do significado. (GEERTZ, 1978, p.15).

Geertz (1978), no desenvolvimento do seu trabalho, comenta alguns conceitos de cultura e critica, principalmente, a confusão teórica que se criou em torno das discussóes sobre o tema, sobretudo na antropologia. Discorre, igualmente, sobre o papel do antropólogo, que deve tentar situar-se no ambiente de observação, na comunidade 'estranha' - e assim poder estabelecer um diálogo com o outro.

da pesquisa antropológica, entre eles: Melville J. Herskovits, Georges Balandier, Robert Redfield, Ralph Linton, H.G. Barnett. 
Quando se compreende a cultura do outro, o que antes era opacidade transformase em entendimento; o que era 'estranho' passa a ser compreensível dentro do quadro de referência que tomamos em consideração. Este é o ponto que o autor considera central, isto é, uma abordagem semiótica da cultura pode auxiliar o trabalho do pesquisador no sentido de fornecer o acesso necessário ao mundo conceitual no qual vivem os indivíduos de uma determinada realidade social. No entanto, como observa Geertz, 'estar situado', obter o acesso à teia de significados de uma determinada realidade social náo significa 'tornar-se nativo' ou tentar copiá-los. O que caracteriza o empreendimento científico do antropólogo é a busca por estabelecer um diálogo com o outro, é conversar com ele, mas não como se falasse com estranhos.

Nesse sentido, para Geertz (1978, p.24), “[...] o objetivo da antropologia é o alargamento do universo do discurso humano". Ele argumenta também que, especialmente sob este ponto de vista, o conceito semiótico de cultura se adapta muito bem:

Como sistemas entrelaçados de signos interpretáveis [...], a cultura não é um poder, algo ao qual podem ser atribuídos casualmente os acontecimentos sociais, os comportamentos, as instituiçóes ou os processos; ela é um contexto, algo dentro do qual eles podem ser descritos de forma inteligível - isto é, descritos com densidade.

A interpretação desse sistema complexo e entrelaçado de signos seria a principal função do pesquisador, daquele que deseja "ler" a cultura do outro. Esta tarefa, no entanto, deve ser feita atentando-se sempre, com exatidão, para o fluxo do comportamento ou ação social, através do qual as formas culturais articulam-se. Elas também encontram articulação nos artefatos e nos vários estados de consciência, os quais marcam os seus significados através do papel que desempenham no contexto social. Os textos dos antropólogos seriam, eles mesmos, segundo Geertz, interpretaçóes de segunda e terceira mão, pois somente um nativo pode fazer uma interpretação em primeira máo da sua própria cultura. Desse modo, o ponto central da abordagem semiótica da cultura, nas palavras de Geertz (1978, p.34-35), seria “[...] auxiliar-nos a ganhar acesso ao mundo conceptual no qual vivem os nossos sujeitos, de forma a podermos, num sentido um tanto mais amplo, conversar com eles.", não buscando compreender o discurso social bruto, ao qual o pesquisador tem apenas um acesso limitado, mas apenas a pequena parte dele que os informantes podem levá-lo a compreender. Ou seja, dentro de uma determinada especificidade complexa e sua circunstancialidade, "[...] poder pensar não apenas realista e concretamente 'sobre' eles, mas, o que é mais importante, criativa e imaginativamente 'com' eles".

Uma das principais forças da descrição ou concepção de cultura de Geertz é o fato de que, como intensamente argumenta ao longo de seu trabalho, a concebe como uma 
complexa teia de significados, os quais inscrevem-se e são inscritos no fluxo permanente da ação social, ou seja, ela náo pode ser considerada como algo que existe de per si, como um fenômeno que exerce as suas "forças" independentemente do acontecimento. Ou seja, apartar a cultura do que acontece, "[...] do que, nessa ocasião ou naquele lugar, pessoasespecíficas dizem, o que elas fazem, o que é feito a elas, a partir de todo o vasto negócio do mundo - é divorciá-la das suas aplicaçôes e torná-la vazia." (GEERTZ, 1978, p.28).

Ver a cultura nesta perspectiva ajuda-nos a iluminar o trabalho do professor de línguas, de modo geral, e do professor de PLE/PL2 de modo específico, o qual deve reconhecer que ao ensinar língua, está ensinando sujeitos a viverem em outra cultura, cuja língua é a sua dimensão primeira. Fazendo um paralelo com o que nos diz Geertz, dissociar a língua da vida, do que as pessoas fazem e pensam, de toda a dimensão cultural e histórica que as abriga é torna-la sem vida, sem sentido, sem função. Por isso importa para o professor compreender a cultura em sua dimensão simbólica, história e complexa, sempre atravessada pela mudança e pelo movimento e contato com outras línguas e culturas.

\section{Ainda hoje, a cultura}

As questóes que ressaltei e trouxe para a reflexãoaté o momento, de maneira geral, ajudaram a integrar um novo conjunto de princípios e atitudes para a compreensão das diferentes realidades sociais e suas relaçôes entre si, não só no âmbito restrito da antropologia, que sempre representou o ambiente original para as discussões sobre cultura, mas também em outras áreas do conhecimento, sobretudo dentro das ciências sociais, e, como já destaquei antes, tornou-se interesse recorrente no campo da Linguística Aplicada. As mudanças evidentes a partir de uma revisitaao conceito de cultura implicam na percepçáo de que o que era estaticidade, passou a reger-se pela dinâmica; o homogêneo, hermético e imutável, cede lugar ao múltiplo, aberto e mutável, numa tentativa de acompanhar o fluxo cada vez mais rápido de mudanças, estruturação e desestruturação pelo qual vem passando o nosso mundo.

Para continuarmos a pensar nessas mudanças, eu gostaria de retornar a Clifford Geertz, mas um Geertz posterior àquele que produziu, como já apontei anteriormente, uma das obras mais representativas sobre o estudo da cultura: $A$ interpretação das culturas. Em trabalhos posteriores, Geertz reafirma a sua busca em rever, reinterpretar os seus próprios conceitos e observa que o impacto das suas ideias, em considerar a cultura como um processo simbólico, já não assusta tanto quanto à época do seu surgimento, há mais de trinta anos. Em sua opiniáo, as ciências sociais, de uma maneira geral, influenciadas por pensadores do século XX, estão-se tornando cada vez mais pluralistas - qualquer proposta de uma "teoria geral" sobre qualquer aspecto social parece-lhe cada vez mais vazia. A antropologia, sobretudo nas discussóes sobre a cultura, também tem acompanhado o movimento 
frenético do pensamento contemporâneo, buscando redimensionar o seu próprio campo de atuação. Mas, de acordo com Geertz (2001, p.28), isso não significa que se esteja estilhaçando, perdendo a sua unidade ou identidade própria, como alardeiam alguns. Para ele, "[...] unidade, identidade e consenso nunca existiram e a ideia de que existiam é o tipo de crença folclórica a que sobretudo os antropólogos deveriam opor resistência."

$\mathrm{Na}$ visão de Geertz, considerando o seu próprio trabalho e a auto-imposição de abrir caminhos e continuar a "dizer B, além de A", o estudo interpretativo da cultura traduz um esforço para a aceitação da diversidade "[...] entre as várias maneiras que seres humanos têm de construir suas vidas no processo de vivê-las". (GEERTZ, 1997, p.29). Mais ainda:

Ver-nos como os outros nos veem pode ser bastante esclarecedor. Acreditar que outros possuem a mesma natureza que possuímos é o mínimo que se espera de uma pessoa decente. A largueza de espírito, no entanto, sem a qual a objetividade é nada mais que auto-congratulação, e a tolerância apenas hipocrisia, surge através de uma conquista muito mais difícil: a de ver-nos, entre outros, como apenas mais um exemplo da forma que a vida humana adotou em um determinado lugar, um caso entre casos, um mundo entre mundos. Se a antropologia interpretativa tem alguma função geral no mundo, é a de constantemente re-ensinar esta verdade fugaz. (GEERTZ, 1997, p.30).

As ideias de Geertz ecoam com muita propriedade ainda hoje, quando o século XXI nos interpela sobre a necessidade de compreendermos a diversidade humana que caracteriza as nossas sociedades contemporâneas e encontrarmos caminhos para lidar com toda essa complexidade. Se pensarmos então na educação linguística em LE/L2 e na formação de professores de línguas, facilmente percebemos como compreender a(s) cultura(s) e sua(s) língua(s) em uma nova chave interpretativa é essencial para atendermos às demandas educacionais do nosso tempo.

Assim como os trabalhos de Clifford Geertz e de outros estudiosos sobre a cultura, podemos conferir, no pensamento contemporâneo e fora do âmbito específico da antropologia, diferentes iniciativas no sentido de reavaliar ou redimensionar a ideia de cultura e as questóes a ela relacionadas. Como exemplo, cito uma linha de argumentos cujo foco principal são as relaçóes sociais e suas implicaçóes. Aqui estou me referindo a uma certa redescoberta da cultura sob o ponto de vista da organização social e seu funcionamento. Este tipo de discussão tem sido bastante fértil, na última década, devido a um certo retorno às ideias difundidas pela sociologia clássica, que atribuía à vida em sociedade a explicação dos fenômenos humanos, dentre eles a cultura.

Num trabalho intitulado $A$ redescoberta da cultura, Simon Schwartzman (1997) nos apresenta uma descrição de cultura como um fenômeno sociológico, que pode ser compreendido a partir do conjunto de conceitos e elementos que caracterizam 
a vida em sociedade ${ }^{4}$, numa espécie de retomada das ideias da sociologia clássica, a qual supunha que todos os fenômenos humanos podiam ser explicados a partir da organização social e da interação entre os indivíduos na sua vida familiar, na divisão do trabalho e na ocupação e defesa do espaço e território.

O termo 'redescoberta' tem a sua motivação no fato de que as teorias culturalistas, segundo o autor, assim como a herança dos clássicos, tornaram-se insuficientes para a compreensão de alguns dos fenômenos mais importantes do mundo contemporâneo, tanto na economia e na política, como na vida social de uma maneira geral. As respostas comuns a problemas específicos, como as diferenças de participação política, mobilização social e aderência aos valores comuns entre diferentes grupos e sociedades não mais podem ter como resposta satisfatória a questão da raça ou respostas estritamente sociológicas, ou, ainda, como afirma Schwartzman (1997, p.46-47), “[...] o caminho pantanoso da cultura”. É necessário que, como afirma o autor, a cultura possa ser compreendida a partir de algo inteligível, "[...] de um conjunto claro, explícito e simples de conceitos referidos às condiçóes de vida em sociedade e com grande poder de explicação." Desse modo, de acordo com a teoria proposta, os valores e crenças dos membros de uma determinada realidade social, compartilhados na vida cotidiana, são as suas "orientaçôes culturais", que também mantêm relaçôes entre si. A cultura, sob esse ponto de vista,

[...] é um modo de vida (way of life) que integra, de forma viável, orientaçóes culturais e relaçôes sociais. Essa viabilidade depende da coerência entre as orientaçôes culturais e as formas de interação social, o que depende, por sua vez, da estrutura social da qual os indivíduos participam. (SCHWARTZMAN, 1997, p.47).

Segundo o autor, no entanto, a força da teoria sociológica da cultura não está nessas definiçóes, mas na forma de permitir compreender-se a estrutura social na qual os modos de vida se acomodam e se apoiam. A estrutura social, sob esse ponto de vista,

[...] seria formada por duas variáveis básicas: a intensidade das relaçôes de solidariedade entre os indivíduos (a força do grupo, ou da comunidade) e o contexto mais ou menos estratificado, as estruturas de diferenciação, autoridade e hierarquia em que os grupos e indivíduos se inserem (a intensidade da grade ou hierarquia). (SCHWARTZMAN, 1997, p.47).

\footnotetext{
A teoria sociológica da cultura defendida por Simon Schwartzman baseia-se nas ideias de Michel Thompson, Richard Ellis e Aaron Wildawski, autores do trabalho Cultural theory, publicado pela Westview Press, 1990.
} 
A partir destas variáveis surge, então uma tipologia bastante simples, que representaria diferentes modos de vida: culturas igualitárias, fatalistas, individualistas e hierárquicas5.

Schwartzman (1997) afirma que é possível discutir a abrangência descritiva desses 'modos de vida' no sentido de demonstrar a sua aplicação nas diferentes situaçóes do convívio social, o que seria uma tentativa de substituir com sucesso a infinidade de explicaçóes culturais produzidas pela antropologia e pela literatura de uma maneira geral. $\mathrm{O}$ autor apresenta dois principais argumentos a favor dessa teoria. $\mathrm{O}$ primeiro deles relaciona-se ao fato de que os 'modos de vida' não são considerados "no vazio", mas situados de forma causal e funcional em estruturas sociais, mesmo que estas sejam definidas de forma muito simples. Decorre disso o fato de que nem todos os "modos de vida" são compatíveis com todas as estruturas sociais. O segundo diz respeito ao fato de que, em qualquer sociedade, os indivíduos se vinculam a grupos e grades de maneiras distintas, desenvolvendo suas próprias perspectivas e valores sobre o funcionamento da estrutura social e combatendo aqueles 'modos de vida' que lhes sáo estranhos. Schwartzman (1997) conclui que esses 'modos de vida', na verdade, são estratégias de organização e ação social, as quais podem ser adotadas ou não pelos indivíduos, a depender do contexto e situação em que vivem.

Além dos dois principais argumentos referidos, Schwartzman (1997) ressalta que a teoria tem demonstrado a sua relevância e força explicativa pelo interesse que tem despertado em inúmeros estudiosos, os quais a têm aplicado a diferentes situaçóes nos últimos anos, cujos resultados mostraram-se bastante sugestivos. O próprio autor especula se essa tipologia poderia nos auxiliar a compreender os problemas relativos à implantação de uma cultura letrada e uma cultura universitária no Brasil.

Schwartzman (1997), com base em suas análises preliminares das culturas em questão, afirma a relevância da teoria por esta possibilitar a reflexão clara e objetiva sobre questões que, segundo ele, são comumente obscurecidas pelas correntes culturalistas e qualitativistas das ciências sociais hoje. Ele próprio admite, no entanto, que a tipologia proposta pela teoria apresenta-se demasiadamente simples para que possa dar conta

\footnotetext{
No igualitarismo, que é característico de grupos coesos, todos controlam as açóes de cada um e não existem pressões externas significativas. Atitudes novas não são permitidas, a não ser por um longo processo de negociação grupal, assim como não são permitidos conflitos e divergências, os quais podem ser interpretados como traição ao grupo. O fatalismo é o extremo oposto do igualitarismo, e caracteriza o grupo que é débil, no qual as estruturas de poder e autoridade são poderosas e onipresentes. O indivíduo não é dono do seu destino e sofre constantemente a ação e o poder do sistema no qual está inserido. No individualismo, as pessoas são livres para agir, pois não sofrem pressões dos grupos e das hierarquias. O mundo não está dado, não existem preceitos rígidos, tudo está por construir e depende do esforço de cada um. E, finalmente, nas culturashierárquicas, os indivíduos são amarrados a grupos e estes, por sua vez, são amarrados a sistemas de dominaçáo e autoridade bem definidos, nos quais cada um tem o seu papel e o seu lugar na estrutura. Não existe igualdade social, nem no sentido individualista, que pensa que pode fazer o que quer, nem no igualitário, que não admite que outros possam ser diferentes dele. Para maiores detalhes sobre cada um destes "modos de vida", vide Schwartzman (1997).
} 
dos múltiplos aspectos que caracterizam a complexidade da vida em sociedade. Por seu caráter abstrato e a-histórico, por exemplo, nem sempre é possível aplicá-la a culturas concretas e determinadas historicamente, além de não permitir que se possa compreender como se originam as estruturas sociais e como se processam as mudanças no interior destas, ou ainda, como se organizam as diferentes posiçôes em um sistema de estratificação social.

No caso específico do Brasil, parece-me que a teoria e o seu quadro tipológico nem sempre podem dar conta, ou, pelo menos, estabelecer uma análise objetiva e coerente da complexa realidade social e cultural que o caracteriza, por mais reduzido que seja o recorte que se tome para análise. No caso, por exemplo, da educação no Brasil, seria preciso mais do que a explicaçáo de um certo predomínio da 'cultura fatalista' para dar conta das diferentes realidades educacionais dentro do próprio país, dos momentos históricos nos quais estáo inseridas, além dos movimentos de estagnação e mudança que determinam as características de cada uma delas. Se considerarmos a educação linguística em língua estrangeira, por exemplo, a complexidade ainda é maior, visto que para nós que atuamos na área de português língua estrangeira / língua segunda não nos bastaria traçar um quadro explicativo do que seja a cultura brasileira e sua relação com a língua que ensinamos, justamente pela impossibilidade de mapearmos aquilo que é movediço e mutável, além de altamente diverso e complexo.

O meu objetivo, ao fazer referência à teoria sociológica da cultura, é demonstrar que as discussôes sobre a cultura, longe de se arrefecerem diante do turbilhão de ideias e contra-ataques surgidos a partir, sobretudo, da segunda metade do século XX, estão cada vez mais vivas, não só no seio da disciplina que a edificou, a antropologia, mas em diferentes campos do conhecimento. Assim como a iniciativa apresentada no âmbito da sociologia, outras têm surgido no interior de áreas como a psicanálise, a literatura, a semiótica etc. No entanto, ao lado de uma certa busca contemporânea em se redescobrir e rediscutir a cultura, há um movimento inverso, em algumas teorias, sobretudo influenciadas pelo advento da globalização, em deslocar a cultura para um espaço secundário, desmitificá-la.

Por ora, o que é importante ressaltar, e eu tenho insistido nisso, é que, independente da área de estudo ou interesse particular, a ideia de cultura e, consequentemente, a busca por conceitos mais limitados, cientificamente mais poderosos, têm sido um dos campos mais férteis de reflexão na evolução do pensamento humano, preocupação que se estende da Antiguidade clássica até os dias de hoje. Se, por um lado, muitos atribuem à noção de cultura e toda a teia que se construiu em volta dela, a confusão conceitual e o terreno escorregadio que se criou sobre o tema, por outro, não se pode negar que a compreensão do fenômeno humano, em toda a sua diversidade, qualquer que seja o ponto de vista a partir do qual olhamos, nâo pode ser desprendido dessa dimensão de significados e de suas relaçóes dentro da vida em sociedade, quer a chamemos de cultura ou utilizemos qualquer outro termo, entre tantos que estão na moda. Para nós, 
professores de línguas estrangeiras, essa compreensão torna-se fundamental, de modo a podermos conduzir as nossas açóes em sala de aula, preparando os nossos alunos para a vida em outra chave simbólica, dentro da qual se encontra a língua-cultura que aprendem.

\section{Um olhar sobre a cultura e o ensino de LE/L2 - considerações finais}

Ao falar de cultura, fico sempre com a sensação de que algo me faltou, algo ficou sem ser dito ou explicado, a teia não se fechou ou apresenta uma trama esparsa. Talvez tenha sido esse o sentimento que moveu e tem movido aqueles que se ocuparam em falar da cultura ou tentar compreendê-la. O que fica claro para mim, no entanto, é que esse pequeno arco do tempo que tentei construir denota que a ideia de cultura e suas implicaçóes para a compreensão do 'estar no mundo' do homem foi, e continua a ser, ainda que em tempos de fragmentação, desconstrução e reestruturaçôes constantes, uma das principais preocupaçóes do pensamento humano.Nesse breve apanhado, apenas pretendi dar uma pequena amostra de algumas concepçóes sobre cultura, para podermos dar início à nossa tarefa de reafirmar a importância dessa compreensão para o campo do ensino-aprendizagem de línguas, estrangeiras e segundas, e, sobretudo, para a formação de professores de PLE/PL2.

A partir desta exposição, e complementando-a, eu desejo ressaltar que cada um dos diferentes conceitos de cultura, com suas distintas nuances, é igualmente válido ou passível de consideraçáo. Ou seja, cada um deles valoriza aspectos variados dentro da ideia de cultura, os quais funcionam como peças complementares de uma mesma engrenagem.

A questão que se impóe não é definir/escolher que tipo de conceito ou definição de cultura melhor se adapta aos objetivos deste artigo, já que podemos optar por um dos diferentes caminhos a partir da encruzilhada, mas edificar um arcabouço teóricometodológico que possa servir de instrumento para uma discussão maior sobre um ensino/aprendizagem de línguas que seja culturalmente sensível aos participantes do processo, e para a reflexão sobre a sua relevância. Náo é o conceito que modela a prática, ao contrário, é o fazer e desfazer, é a busca por instrumentos, materiais e modos de agir em sala de aula que nos auxilia a montar o quebra-cabeça conceitual que servirá de esteio para a nossa reflexão. Dessa forma, a visão sobre cultura que apresento a seguir não tem a pretensão de funcionar como um bloco acabado de definiçóes sobre essa importante dimensão da nossa vida, mas principalmente destacar alguns princípios norteadores que ajudem a iluminar o processo de formar professores e de ensinar e aprender línguas, bem como as práticas que realizamos em sala de aula de LE/L2. Para construirmos uma ideia mais aberta e flexível de cultura, devemos compreender que ela: 
a) engloba uma teia complexa de significados que são interpretados pelos elementos que fazem parte de uma mesma realidade social, os quais a modificam e são modificados por ela. Esse conjunto de significados inclui as tradiçôes, os valores, as crenças, as atitudes e conceitos, assim como os objetos e toda a vida material;

b) não existe sem uma realidade social que lhe sirva de ambiente; ou seja, é a vida em sociedade e as relaçóes dos indivíduos no seu interior que vão moldar e definir os fenômenos culturais, e não o contrário;

c) não é estática, um conjunto de traços que se transmite de maneira imutável através das geraçōes, mas um produto histórico, inscrito na evolução das relações sociais entre si, as quais transformam-se num movimento contínuo através do tempo e do espaço;

d) não é inteiramente homogênea e pura, mas constrói-se e renova-se de maneira heterogênea através dos fluxos internos de mudança e do contato com outras culturas;

e) está presente em todos os produtos da vivência, da ação e da interação dos indivíduos; portanto, tudo o que é produzido, material e simbolicamente, no âmbito de um grupo social é produto da cultura desse grupo.

Diante desse quadro que tracei para a compreensão da cultura, e como eu venho afirmando em outros textos (MENDES, 2011, 2014), para nós que atuamos no campo do ensino-aprendizagem de PLE/PL2 importa compreender que ao ensinarmos língua, estamos ensinando uma língua-cultura. Isso significa que reconhecemos o português como um fenômeno social e simbólico de construção da realidade que nos cerca, o modo de construirmos os nossos pensamentos e estruturarmos as nossas açóes e experiências e as partilharmos com os outros. Ele também representa um sistema complexo, que envolve diferentes níveis de estruturas formais, como os aspectos fonológicos, morfológicos, sintáticos e semânticos, as unidades de sons e suas representaçôes gráficas, assim como um sistema de normas e regras de organização e combinaçãoo dessas estruturas. Mas não apenas isso. Envolve, também, um conjunto de códigos sociais e culturais, inscritos em processos históricos mais amplos e que não podem ser negligenciados.

A língua portuguesa, como língua pluricêntrica, apresenta diferentes normas de uso, de acordo com as diferentes variedades que representam os diferentes países que a têm como língua oficial. Desse modo, ao falarmos do português, devemos compreendê-lo como uma língua comum, mas que traz diferentes matrizes ideológicas, identitárias e culturais, ou seja, uma mesma língua representada por diferentes línguas-culturas. Isso não significa, como defendem muitos, que devamos ensinar essa língua sempre fechando-a em uma visão de país ou cultura específica, mas o contrário. O que tenho almejado como formadora de professores de PLE/PL2 e também coordenadora de 
projetos de ensino, de produção de materiais e de promoção linguística, em diálogo com muitos colegas com os quais tenho trabalhado, em diferentes países que integram a comunidade lusófona, é uma gestão multilateral da língua portuguesa, com reflexos, sobretudo, nos modos como ensinamos essa língua e a projetamos como língua de força global. Ou seja, uma gestão multilateral significa que todos participam nas decisões de promoção e no desenvolvimento de projetos de formação e de ensino da língua. Além disso, uma visão partilhada da língua também se reflete nos princípios e perspectivas teórico- metodológicos que orientam o ensino e a formaçáo de novos professores. Sendo assim, ao ensinar língua portuguesa, estamos também ensinando diferentes modos de ancoragem cultural, diferentes modos de ser e de estar no mundo em português.

E como essas questôes afetam o que fazemos quando ensinamos e aprendemos uma LE/L2 como o português? Com a compreensão diferenciada da língua e de sua relação com a cultura, a questão não se resume a apenas introduzir o cultural como um conjunto de conteúdos ou temas que, ao lado do gramatical ou outros conjuntos conceituais, representam a totalidade de uma língua. Aprender uma língua como o português, por exemplo, seria mais do que dominar uma cultura de ilustração, mas aprender a estar socialmente em português, o que envolve muito mais coisas do que simplesmente o domínio de formas linguísticas e de curiosidades culturais sobre a língua-alvo do Brasil ou de Portugal ou de Angola.

Mais do que um instrumento, a língua é um símbolo, um modo de identificação, um sistema de produção de significados individuais, sociais e culturais, uma lente através da qual enxergamos a realidade que nos circunda. Ao estruturar os nossos pensamentos e açóes, ela faz a mediação entre as nossas experiências e a do outro com o qual interagimos socialmente através da linguagem, auxiliando-nos a organizar o mundo à nossa volta. Nesse sentido, a cultura não está antes nem depois da língua, nem uma dentro da outra, mas estão no mesmo lugar, como afirma Almeida Filho (2002, p.210): “[...] o lugar da cultura é o mesmo da língua”.

Assim, ensinar PLE/PL2 buscando novas perspectivas teóricas e metodológicas significa estar aberto para compreender a língua em uma nova chave, como instância de uso e de interação, como resultado de práticas de significação situadas e marcadas historicamente, e que, por isso mesmo, náo podem estar dissociadas da cultura. Esta, por sua vez, não pode ser vista como superestrutura, como conteúdo a ser aprendido ou como conjunto de informaçóes sobre um país ou grupo social. Antes, deve ser compreendida como matriz simbólica, como rede de significados que vamos compondo à medida que vivemos e interagimos com outros. A partir dessa compreensão, as açôes que desenvolvemos em sala de aula devem ser voltadas para ensinar os nossos alunos não a gramática fria e estanque, mas modos de ser e de viver em português, língua viva e cheia de tantos matizes quantos são os seus falantes, nos quatro continentes onde é falada como língua oficial, nas diferentes comunidades de falantes que vivem nas diásporas, em diferentes partes do mundo, e também através de todos aqueles que se 
apropriaram dela, inicialmente como língua estrangeira, e que agora também vivem em português. É está riqueza que nos faz grandes e ricos culturalmente - saibamos, pois, levá-la para a nossa sala de aula.

\section{THE IDEA OF CULTURE AND ITS TOPICALITY FOR TEACHING-LEARNING LE / L2}

- ABSTRACT: In recent decades, many studies and research developed in the field of teaching I learning languages, especially of foreign and second languages, have been dedicated to discuss the importance of culture and intercultural relations as members of the learning process dimensions. This concern has as principle the fact that teaching and learning a language is a much broader and complex than the simple transmission and apprehension of formal structures and rules of use of these structures process. In this article, I propose to revisit the idea of culture to then establish their relationship with language, emphasizing the relevance of this type of reflection for the teaching-learning area LE / L2, especially focusing in Portuguese. Among other things, I want to show that contemporary trends in teaching and language teacher training recognize that approaches to teaching and learning, whatever their theoretical orientations should not isolate the language of life in which we live and culture or cultures as a means to ensure language education quality and consistent with the requirements of the contemporary world.

- KEYWORDS: Culture concept. Language and culture. Teaching and learning LE. Portuguese foreign language.

\section{REFERÊNCIAS}

ALMEIDA FILHO, J. C. P. Língua além de cultura ou além de cultura, língua? Aspectos do ensino da interculturalidade. In: CUNHA, M. J.; SANTOS, P. (Org.). Tópicos em português língua estrangeira. Brasília: Ed. da UNB, 2002. p.210-215.

CUCHE, D. A noçáo de cultura nas ciências sociais. Bauru: EDUSC, 1999.

GEERTZ, C. Nova luz sobre a antropologia. Rio de Janeiro: Jorge Zahar, 2001.

O saber local: novos ensaios em antropologia interpretativa. Petrópolis: Vozes, 1997.

. A interpretaçáo das culturas. Rio de Janeiro: Zahar, 1978.

LARAIA, R. de B. Cultura: um conceito antropológico. Rio de Janeiro: Jorge Zahar, 1999.

MENDES, E. O ensino do português como língua estrangeira (PLE): desafios, tendências contemporâneas e políticas institucionais. In: ANDREEVA, Y. (Org.). Horizontes do saber filológico. Sófia-Bulgária: Sveti Kliment Ohridski, 2014. p.33-45. 
O português como língua de mediação cultural: por uma formação intercultural de professores e alunos de PLE. In: MENDES, E. (Org.). Diálogos interculturais: ensino e formação em português língua estrangeira. Campinas: Pontes, 2011. p.139-158.

NEIVA, E. Crítica à ilusão antropológica: teoria da cultura diante do fenômeno da Globalização. In: MENEZES, P. (Org.). Signos plurais: mídia, arte e cotidiano na globalização. São Paulo: Experimento, 1997. p.133-161.

SCHWARTZMAN, S. A redescoberta da cultura. São Paulo: EDUSP, 1997. 
